\title{
Structural basis of AMPK regulation by adenine nucleotides and glycogen
}

Xiaodan Li, Lili Wang, X Edward Zhou, Jiyuan Ke, Parker W de Waal, Xin Gu, M H Eileen Tan, Dongye Wang, Donghai Wu, H Eric Xu, Karsten Melcher

Cell Research (2015) 25:398. doi:10.1038/cr.2015.27; published online 3 March 2015

Correction to: Cell Research (2015) 25:50-66. doi:10.1038/cr.2014.150; published online 21 November 2014

The authors apologize for omission of the following funding information in the Acknowledgments section: National Natural Science Foundation of China (grant 31100540 to D Wang). 